\title{
Accessory Leaflet of Tricuspid Valve Masquerading as Infective Endocarditis Preoperatively and Causing RVOT Obstruction Postoperatively
}

\author{
Nishith Bhargava1, Saket Agrawal', Deepak K. Tempe², Deepak K. Satsangi1 \\ ${ }^{1}$ Department of Cardiothoracic and Vascular Surgery (CTVS), GB Pant Hospital (GBPH), New Delhi, India \\ ${ }^{2}$ GB Pant and GNEC Hospitals, New Delhi, India \\ Email: drnishithbhargava@gmail.com
}

Received 10 January 2015; accepted 31 January 2015; published 3 February 2015

Copyright (C) 2015 by authors and Scientific Research Publishing Inc.

This work is licensed under the Creative Commons Attribution International License (CC BY).

http://creativecommons.org/licenses/by/4.0/

(c) (i) Open Access

\begin{abstract}
Accessory tricuspid valve tissue is a rare congenital anomaly. We report a case where preoperative echocardiogram was suggestive of infective vegetations over the tricuspid valve but intraoperatively it was found to be accessory tricuspid valve leaflets which were causing right ventricular outflow tract obstruction.
\end{abstract}

Keywords

Accessory Tricuspid Valve, Endocardial Vegetations, Echocardiogram

\section{Introduction}

It is not always straightforward to distinguish vegetations from a cardiac mass on preoperative echocardiogram. We present a patient with complex congenital heart disease in whom preoperative echocardiogram suggested multiple vegetations over the tricuspid valve which were discovered to be accessory tricuspid valve tissue intraoperatively.

\section{Case Report}

A 17 years old male presented with the complaints of bluish discoloration of tongue since early childhood and dyspnoea on exertion grade 2. He had history of one episode of high grade fever 3 months back for which he 
was hospitalized. On general physical examination he had cyanosis and there were no skin or mucosal stigmata of endocarditis. Cardiac examination revealed a silent precordium. Laboratory examination showed haemoglo-

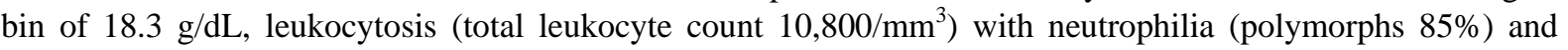
normal renal and liver function tests. On transthoracic echocardiogram [TTE] he was diagnosed to have Tetralogy of Fallot with subaortic ventricular septal defect [VSD] with right ventricular outflow tract obstruction [RVOTO]. In addition multiple large vegetations over tricuspid valve and a small vegetation over mitral valve without notable regurgitation or obstruction were seen. Because of presence of multiple vegetations cardiac catheterization was not done and patient was taken directly for surgery. Blood cultures performed pre-operatively were sterile. Erythrocyte sedimentation rate [ESR] and C-reactive protein [CRP] were within normal limits. Transoesophageal echocardiogram [TEE] performed preoperatively during surgery also revealed large vegetations over the tricuspid valve projecting into the right b ventricular outflow tract (Figures 1-3).

Intra operatively however to our surprise, no vegetations were seen either on the tricuspid valve or on the mitral valve, instead tricuspid valve was found to be redundant and myxomatous with multiple accessory leaflets without any evidence of infective vegetations (Figure 4). Infundibular bands were resected and ventricular septal defect was closed. The accessory leaflet was not excised for fear of causing tricuspid regurgitation. Pulmonary

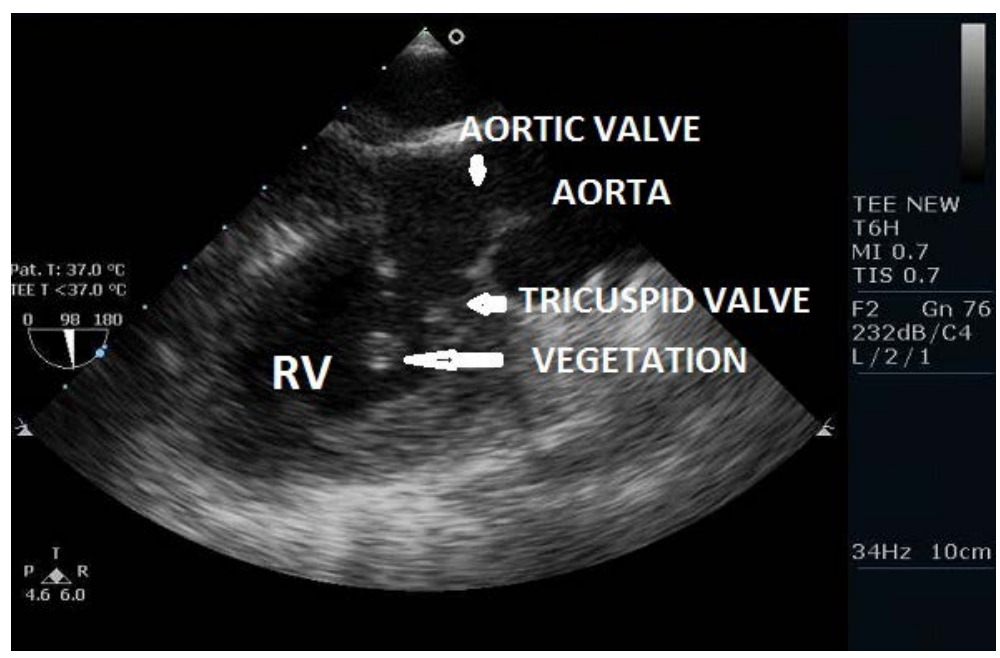

Figure 1. Modified aortic valve long axis view on intraoperative transoesophageal echocardiography showing the accessory tricuspid valve tissue which was thought of as infective vegetation because of its mobility.

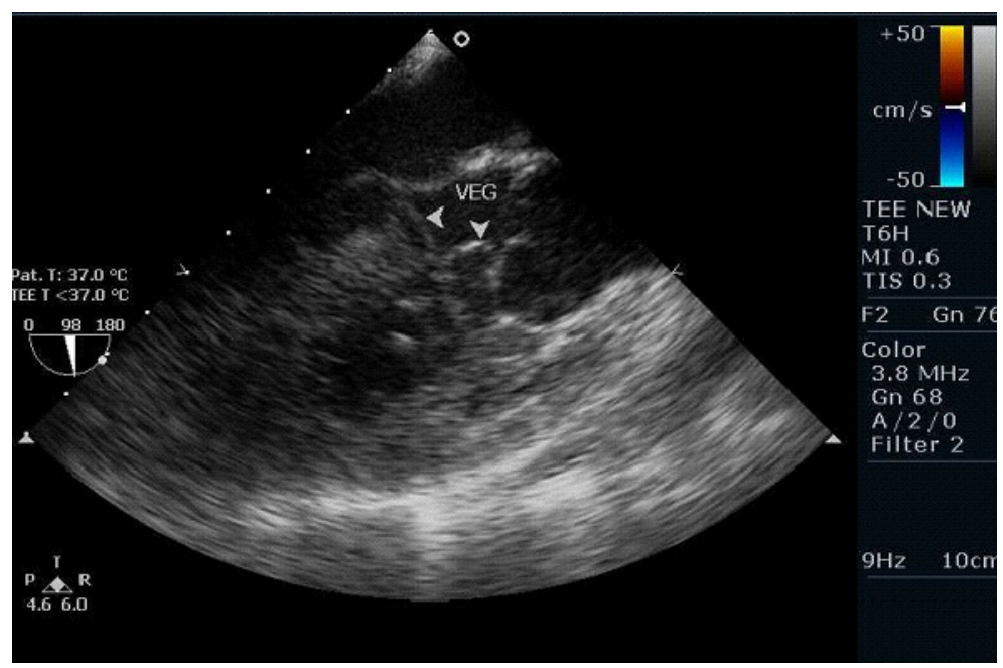

Figure 2. Aortic valve long axis view on intraoperative transoesophageal echocardiography showing the vegetations. 


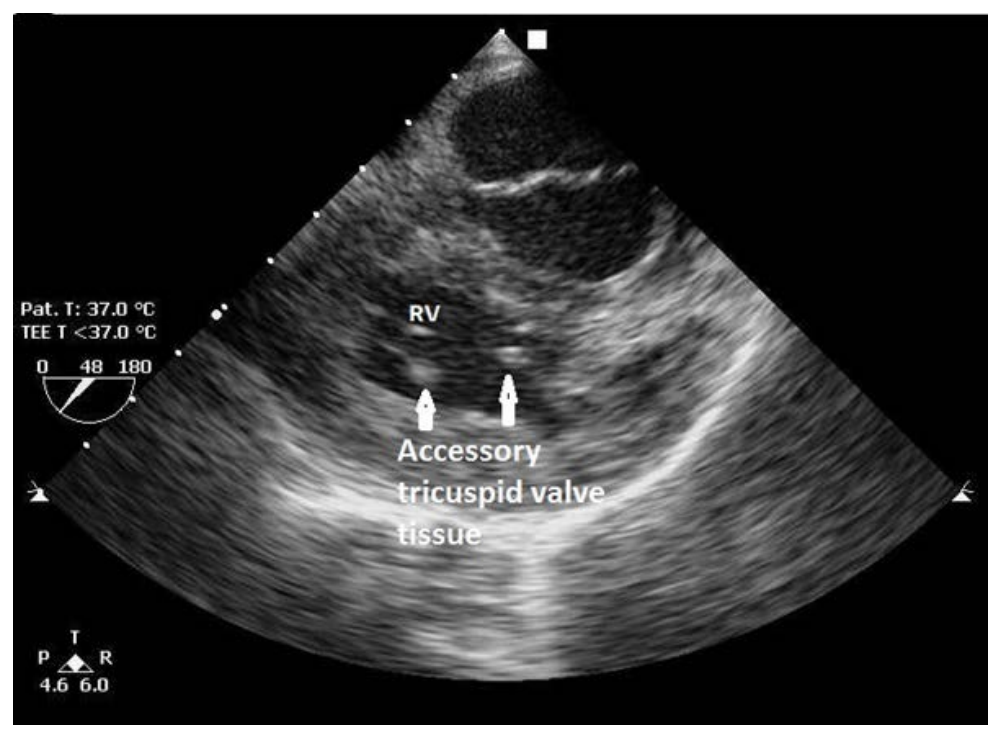

Figure 3. Modified four chamber view on intraoperative transoesophageal echocardiography showing the accessory tricuspid valve tissue misinterpreted as vegetation.

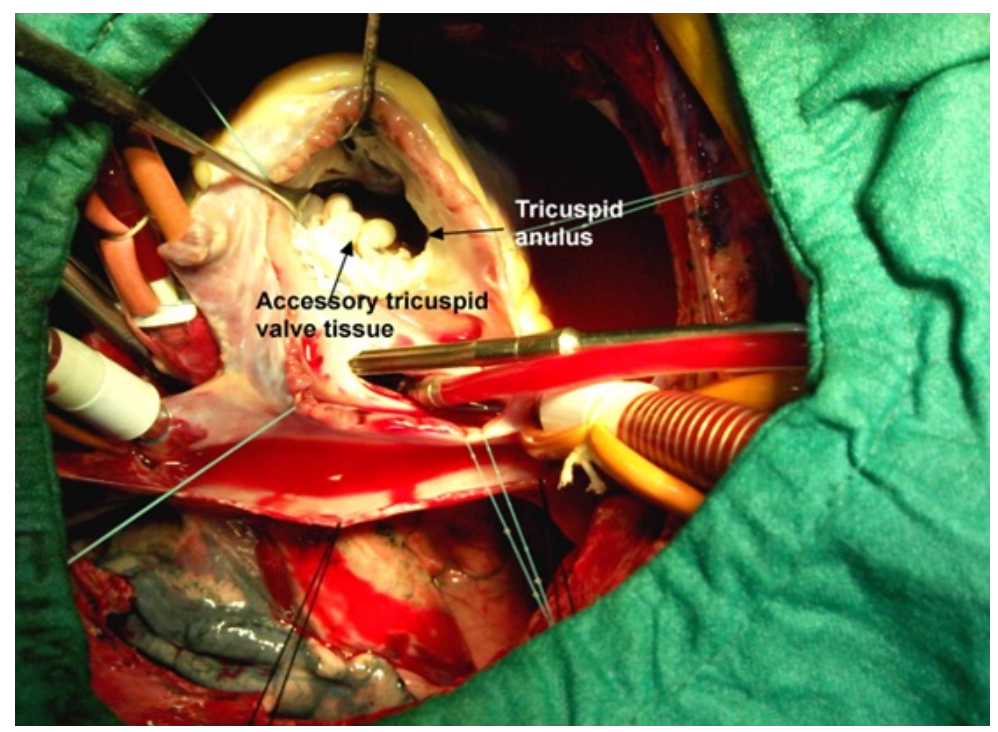

Figure 4. Intraoperative image showing the large accessory tricuspid valve leaflet tissue.

valve was found to be normal. However, on coming off bypass the right ventricular pressure was found to be systemic. Patient was again placed on bypass and a right ventricular outflow tract incision was made. Through the incision it was obvious that the exuberant tricuspid valve tissue was causing RVOTO. A right ventricular outflow tract patch was placed which relieved the obstruction and patient was successfully weaned off cardio-pulmonary bypass with right ventricular to left ventricular pressure ratio of 0.5 .

Patient had an uneventful post operative course and was weaned off from ventillatory support on post operative day 1 and was off ionotropes on post operative day 3. He was discharged from the hospital on 8th post operative day.

\section{Discussion}

Accessory tricuspid valve leaflet is a rare finding. Only a few cases of accessory tricuspid valve have been re- 
ported unlike accessory mitral valve tissue which has been reported more frequently [1]. Accessory tricuspid valve leaflet is frequently associated with other congenital defects, such as tetralogy of fallot, transposition of the great arteries and ventricular septal defects [2]-[5]. Two types of accessory tricuspid valve have been defined: mobile and fixed [2]. The mobile type is a parachute like leaflet floating freely in the right ventricle via a long chordae. The fixed type is firmly anchored to the interventricular septum by short chordae. When associated with VSDs, both types can cause partial to near-complete obstruction of the VSD. Mobile-type accessory tricuspid valve can also cause RVOTO or even the left ventricle outflow tract obstruction by migrating through the VSD.

The diagnosis of accessory tricuspid valve leaflet may be suspected upon noninvasive imaging such as echocardiography, cardiac computed tomography or magnetic resonance imaging. However, definitive diagnosis is achieved by surgical excision and histopathologic analysis that shows marked thickening and fibrosis of the spongiosa layer. Differential diagnosis particularly includes papillary fibroelastoma [6] [7] and other cardiogenic tumors [8]. The diagnosis of papillary fibroelastoma is confirmed by a histopathologic examination showing vascular papillomas with a single layer of endocardial cells covering the papillary surface [6].

\section{Conclusion}

There are no fixed guidelines for management of this anomaly but probably the accessory leaflet should be resected [2] [3] [9] [10] or a pericardial patch placed if it is causing left ventricular or right ventricular outflow tract obstruction as was observed in the present patient. Also that accessory tricuspid valve tissue should come as a differential diagnosis, if echocardiography shows a mobile mass attached to the tricuspid valve.

\section{References}

[1] Yoshimura, N., Yamaguchi, M., Oshima, Y., Oka, S., Ootaki, Y., Tei, T. and Ogawa, K. (2000) Clinical and Pathological Features of Accessory Valve Tissue. Annals of Thoracic Surgery, 69, 1205-1208. http://dx.doi.org/10.1016/S0003-4975(99)01580-5

[2] Faggian, G., Frescura, C., Thiene, G., Bortolotti, U., Mazzucco, A. and Anderson, R.H. (1983) Accessory Tricuspid Valve Tissue Causing Obstruction of the Ventricular Septal Defect in Tetralogy of Fallot. British Heart Journal, 49, 324-327. http://dx.doi.org/10.1136/hrt.49.4.324

[3] Lee, C., Lee, C.H., Kwak, J.G. and Park, C.S. (2010) Isolated Accessory Tricuspid Valve Causing Right Ventricular Outflow Tract Obstruction. Journal of Cardiac Surgery, 25, 410-411. http://dx.doi.org/10.1111/j.1540-8191.2010.01039.x

[4] Mesko, Z.G., Wagner, H.R. and Subramanian, S. (1978) Tetralogy of Fallot. Occlusion of the Ventricular Septal Defect Due to Accessory Tricuspid Valve Leaflet and an Associated Membranous Aneurysm. European Heart Journal, 7, 257-262.

[5] LaCorte, M.A., Boxer, R.A., Singh, S., Parnell Jr., V. and Goldman, M. (1985) Echocardiographic Features of Tetralogy of Fallot with an Accessory Tricuspid Valve Leaflet. American Heart Journal, 110, 1297-1299. http://dx.doi.org/10.1016/0002-8703(85)90029-8

[6] Burke, A. and Virmani, R. (1996) Papillary Fibroelastoma: Tumors of the Heart and Great Vessels. AFIP Atlas of Tumor Pathology, 16, 47-54.

[7] Eckstein, F.S., Schäfers, H.J., Groten, J., Mügge, A. and Borst, H.G. (1995) Papillary Fibroelastoma of the Aortic Valve Presenting with Myocardial Infarction. Annals of Thoracic Surgery, 60, 206-208. http://dx.doi.org/10.1016/S0003-4975(94)01061-7

[8] Song, M.H., Usui, M., Usui, A., Watanabe, T. and Ueda, Y. (2001) Giant Vegetation Mimicking Cardiac Tumor in Tricuspid Valve Endocarditis after Catheter Ablation. Japanese Journal of Thoracic and Cardiovascular Surgery, 49, 255-257. http://dx.doi.org/10.1007/BF02913526

[9] Meldrum-Hanna, W.G., Cartmill, T.B., Hawker, R.E., Celermajer, J.M. and Wright, C.M. (1986) Accessory Mitral Valve Tissue Causing Left Ventricular Outflow Tract Obstruction. British Heart Journal, 55, 376-380. http://dx.doi.org/10.1136/hrt.55.4.376

[10] Ocal Karabay, K., Rizaoglu, E., Paker, T., Bassullu, N. and Karatay, C.E. (2013) Accessory Tricuspid Valve Leaflet in an Asymptomatic Adult. Journal of Clinical Experimental Cardiology, 4, 229. 
Scientific Research Publishing (SCIRP) is one of the largest Open Access journal publishers. It is currently publishing more than 200 open access, online, peer-reviewed journals covering a wide range of academic disciplines. SCIRP serves the worldwide academic communities and contributes to the progress and application of science with its publication.

Other selected journals from SCIRP are listed as below. Submit your manuscript to us via either submit@scirp.org or Online Submission Portal.
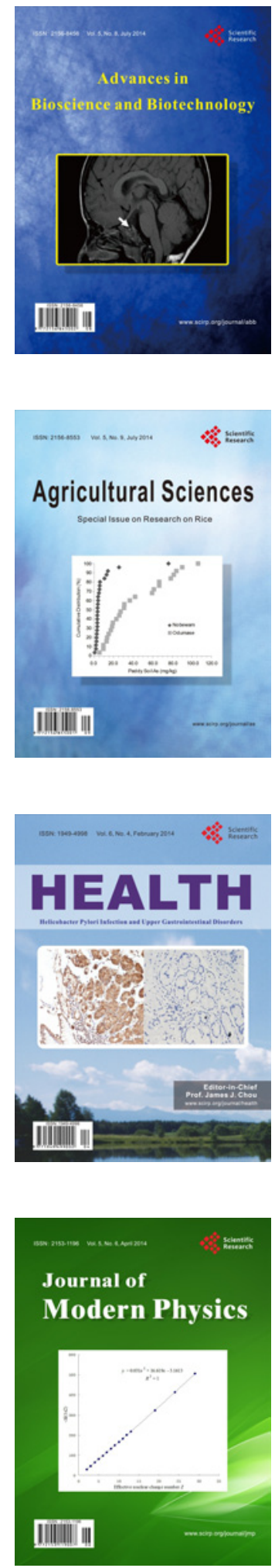
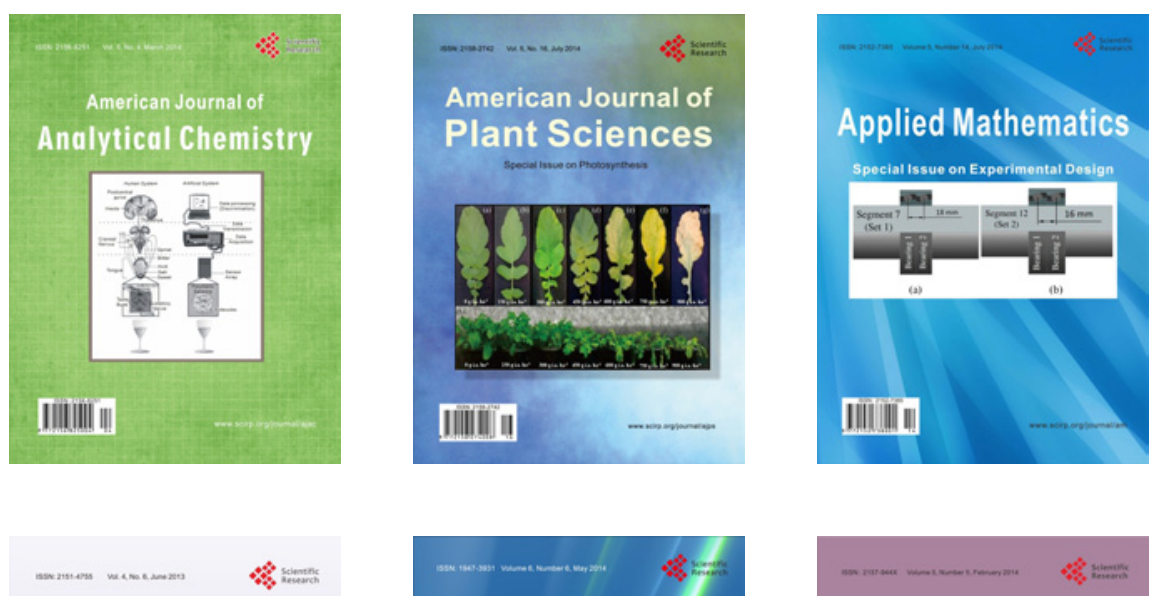

Creative Education
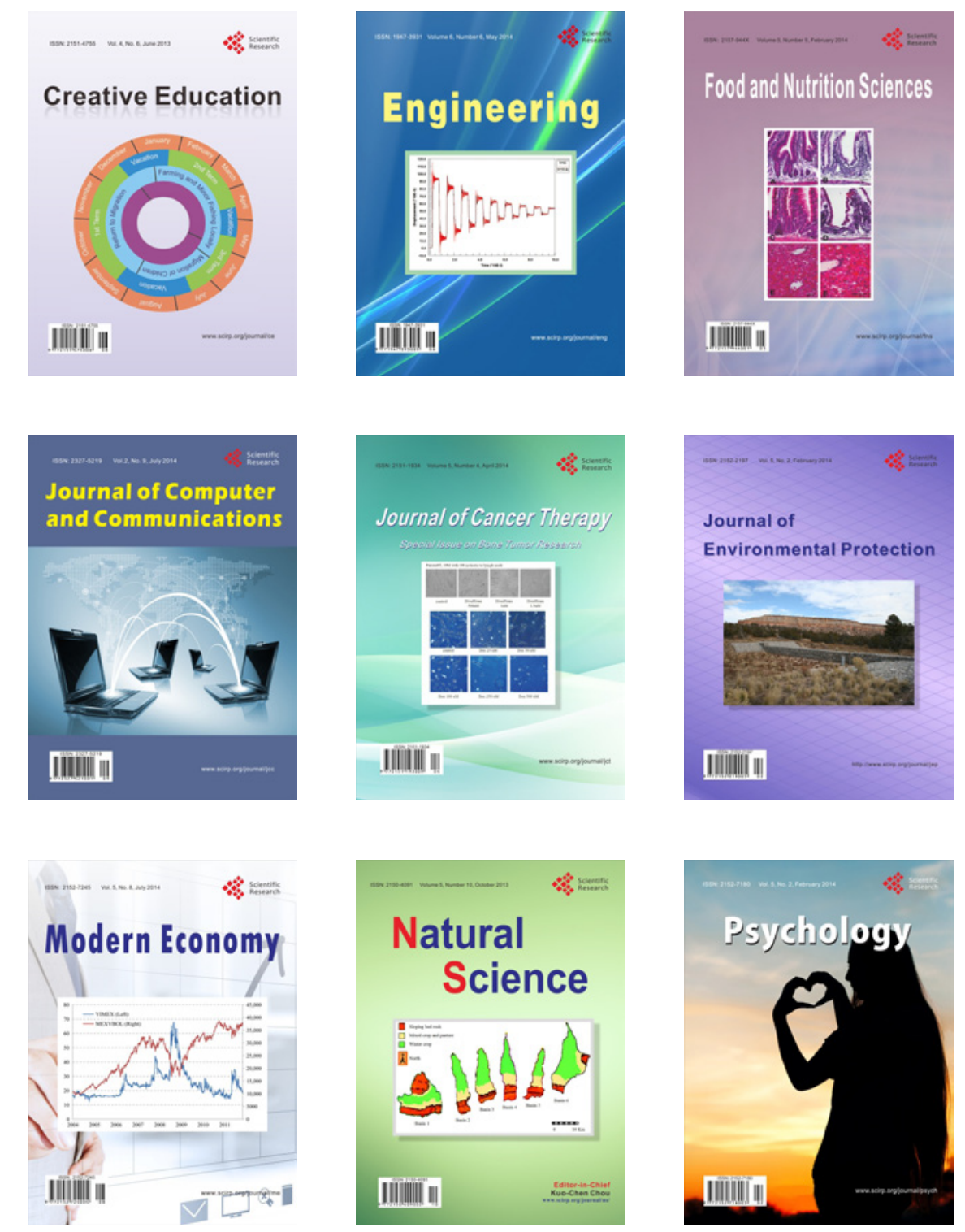